\title{
AGENCY VIEWS
}

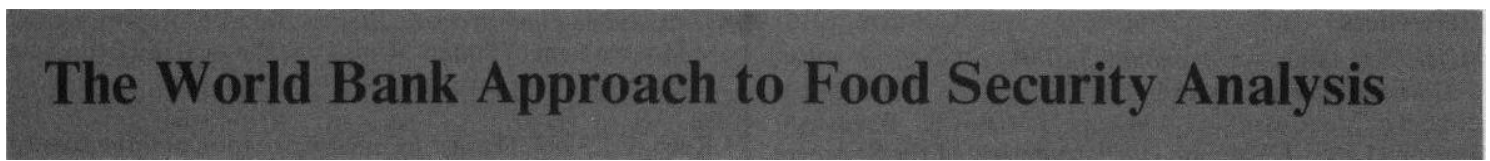

Robert E. Hindle

\section{Introduction}

In July 1988, the Executive Directors of the World Bank approved a Food Security Initiative for SubSaharan Africa. The conceptual framework for the initiative is set forth in a paper prepared by Shlomo Reutlinger, entitled The Challenge of Hunger in Africa. The paper defines food security as 'access by all people at all times to enough food for an active and healthy life'. It also distinguishes between two types of food insecurity: chronic and transitory. Chronic food insecurity is a persistent pattern of ifood deprivation over a long period. Transitory food insecurity is a temporary phenomenon related to the cropping cycle or a sudden shortfall in food access or availability. In agreeing to the definition of Food Security and the conceptual framework set out in this paper, the Board and Management of the World Bank recognised that moving beyond dry and simple definitions and broad conceptual frameworks to practical programmes and projects in Africa is a demanding task. The task, after all, is to reduce hunger in Africa, recognising the time required to do so will be lengthy. As the first step in the initiative, nevertheless, the Bank has undertaken to prepare food security action plans for a set number of African states each year (currently amounting to a total of 14). ${ }^{1}$ Additional plans will be prepared in the future. These food security actions plans are country specific and cover concrete recommendations on the policies, investments and institutions which are critical to food security.

Having launched the initiative, very practical questions about how to 'do' food security analysis arose. Some of these questions were of the 'how is it different?' sort. For instance, Bank staff wanted to know how food security analysis differs from a spectrum of alternatives from simple agriculture sector reviews to general development strategies. Much debate centered on how food security analysis differs, if at all, from nutrition [Riley 1990]. Implicit in these questions was the need to know what is different and/or new about food security as a way to approach African issues. A second type of question moved

Completed action plans: Sudan. Kenva. Mozambique. Malawi. Benin. Cameroon and Madagasear. Action plans under preparation: Burkina Faso. Nigeria and Rwanda. Action plans planned: Ethiopia. Ghana. Chad and Tanzania. beyond differences of approach to the very practical ones of what do I do now? Among Bank staff this was frequently rephrased as: Assuming I want to analyse food insecurity in Chad, what do I do when I get off the plane in Ndjamena?

The purpose of this article is to describe the evolution of thinking within the World Bank as staff have struggled to deal with these questions. The article is divided into two parts: 1) a short section which answers the question of what is new and different about food security analysis; and 2) a longer section which describes the elements of food security analysis at the World Bank.

\section{What's new about food security analysis; or food security revealed}

By definition, initiatives imply something different from what is currently being done. Whether an initiative is totally new, however, in the sense of never having been tried before, is less likely. Particularly in development economics, where intellectual fads seem to change with hemlines, it is likely that any so called initiative is really a restatement or rediscovery of a previously known truth [Arndt 1987]. So the honest answer to the question of what is new about food security is: not much, but it does bring a degree of balance to the school of 'just get the prices right' approach to development. Food security recognises that growth is not enough, just as trickle down was not sufficient. There are other important considerations to add. First while there may be nothing new about food security as a concept, the fact that the World Bank has moved it to the centre of its work on Africa is new. Second, systematic attention to food security analysis leads to different public policy outcomes. This is so, not because it is different, but because it alters the balance of ingredients which go into public policy. While not new, food security is different and this is important.

At risk of oversimplifying, it is probably fair to say it makes a difference when the World Bank identifies an issue and incorporates it into its thinking. Food security is no exception. The difference comes in part from the size of the Bank, its impact on developing countries and its place in setting the agenda for the development debate. While one hopes the Bank's influence on development thinking comes in large part 
from the quality of its work and the persuasiveness and logic of its augmentation, it is likely the influence comes in part from the Bank's size. As a result, simply to pick up an idea which has not previously been part of Bank thinking gives it a currency which is new. (It is this aspect of the World Bank's role which simultaneously strengthens its capacity to have a positive impact on development, and imposes on it a very serious responsibility to act prudently and with understanding of divergent points of view.)

As far as changed outcomes are concerned, the usefulness of food security is the balance it brings to public policy decision making. For reasons which should be clear later, food security focuses policymakers on the human impact of policy decisions as well as highly aggregated macroeconomic indicators. But balance is vital. Aggregate growth strategies which do not look into the distributional impacts of growth strategies (improved welfare for the poorest) may well be unsustainable. Food riots in African states undergoing structural adjustment are an example of this. On the other hand, welfare led development strategies in the absence of aggregate growth have not succeeded in raising the incomes and economic well-being of the poor [Gunatilleke 1988]. So what is new is the balance which food security brings to growth and welfare for Africa. The reasons are straightforward. For the past two decades economic growth has consistently lagged behind population growth in sub-Saharan Africa. As a result, per capita income has remained essentially stagnant since 1961. Moreover, Africa is the one region of the world where human welfare is expected to worsen in the future [World Development Report 1990]. Even though the number of poor in Asia is now higher than Africa, the proportions are the same in Asia and Africa, and Asia's satisfactory growth rates are projected to lead to reduced numbers and levels of poverty.

\section{Food security as an organising principle}

Food security is an outcome (the object of policy is to make people food secure), but it is more importantly an approach to development thinking. It is an organising principle. As a result, one should not expect to see food security projects, but rather food security strategies. Effective food security analysis should direct governments (and donors insofar as they are relevant) to put in place those policies, investments and institution building efforts which are consistent with long term reduction of food insecurity. Food security strategies begin with an identification of who the food insecure are and where they are located. Locating the food insecure (both the chronic and transitory food insecure) is an effective way of mapping poverty in a country. Beginning with an understanding of who are poor helps order the priority of particular interventions and so distinguishes a food security led strategy from others. To use food security as an organising principle, then, the first step is to understand who the malnourished are.

But one still needs an analytical framework to use food security effectively as an organising principle, the framework should be one which links production with consumption, availability with access and macroeconomics with microeconomics. This is a daunting task and clearly only feasible if there is a way to exclude irrelevancies. Food security analysis has five major components:
1) macroeconomics
2) microeconomics
3) food availability
4) food consumption and
5) markets (goods, labour and land)

Before describing each of the components of food security analysis it is useful to present them schematically. (See Figure 1) Recall that the way into the framework is to define who the food insecure are, and the outcome of using it is the essential elimination of food insecurity.

To say that macroeconomic change has an impact on food security is a truism, which like all truisms is of very little use. Taking apart macroeconomic change into its important components and linking it to food availabilities and food consumption is of more use. From a food security perspective, the following kind of macroeconomic changes (which are normally part of structural adjustment programmes) are important: 1) exchange rate and trade reform; 2) fiscal policy; 3) monetary policy; 4) public sector management reform. Up to the present, most analysis of the macroeconomic impact on food security has started by asking: What is the result of a particular policy change on food security? i.e., if a country devalues by $\mathrm{X}$ per cent, what does it mean for the food insecure? $\mathrm{A}$ better way to approach this is the other way round by asking: Given food security as an objective, what are the macroeconomic policies needed to get there? This is the difference between curative and preventive medicine.

Exchange rates and trade reform have the most immediate impact on food availabilities. Correcting for overvalued exchange rates is likely to lead to an immediate reduction of (non food aid) imports and a medium term increase in domestic food production. A result of this is likely to be (and here is where it is necessary to have mapped the food insecure) reduced short term food availabilities in cities, with high prices for both producers and consumers. Whether or not rural areas are better off depends on the proportion of people who are net purchasers of food. This number is rather higher than one would expect in Africa. 


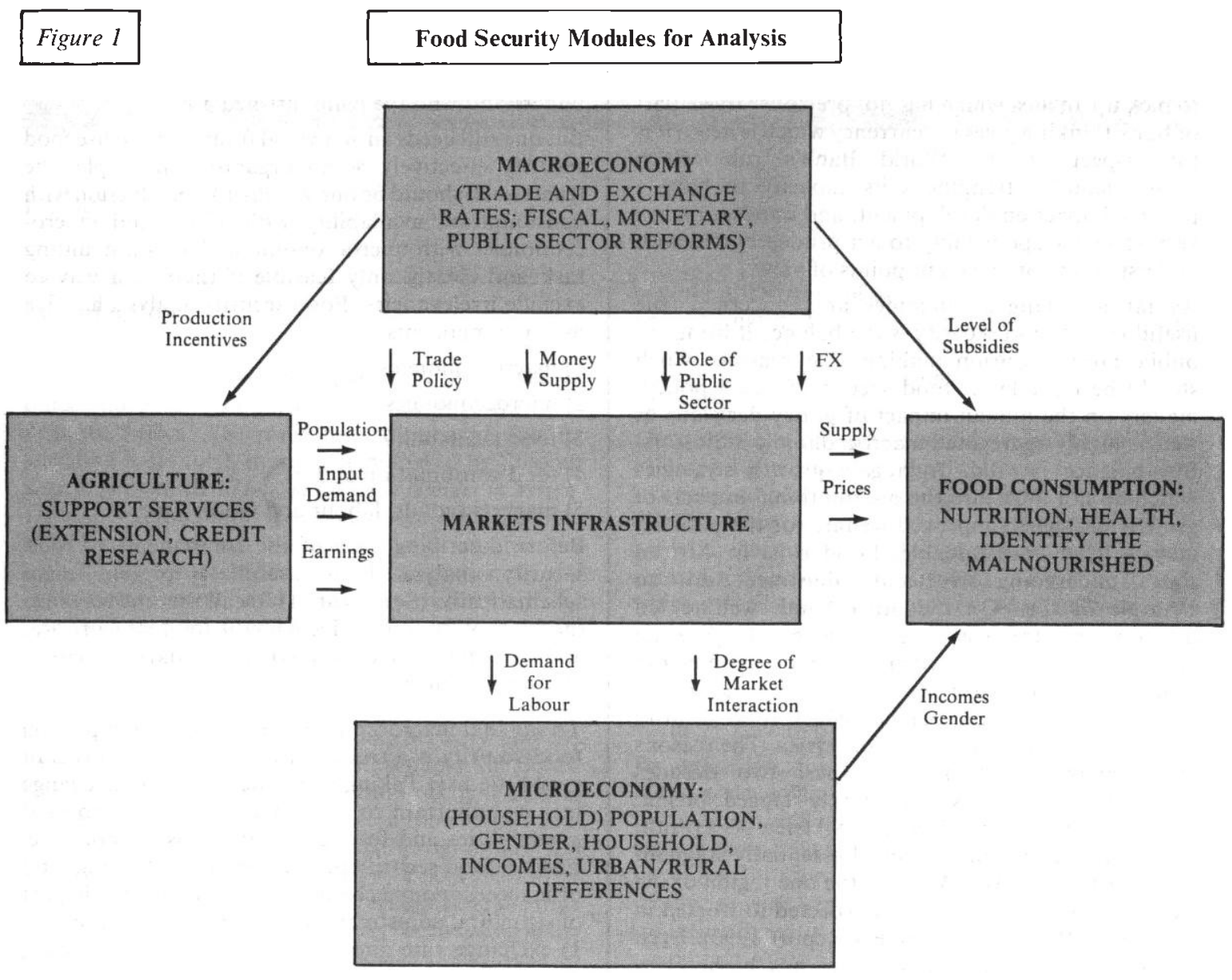

\section{NATIONAL FOOD SECURITY: MACROECONOMY, AGRICULTURE AND MARKETS HOUSEHOLD FOOD SECURITY: MICROECONOMY INDIVIDUAL FOOD SECURITY: FOOD CONSUMPTION}

Similarly, changes in trade policy have an immediate impact on food availability. Fiscal reform affects most immediately food consumption, for the reason that most fiscal reform is designed to reduce unsustainable budget deficits. In some countries (Sudan) a significant portion of the deficit comes from consumer subsidies on food. The only way to move to a more balanced budget is to reduce subsidies, thereby curtailing access of people to food. Again, knowing who the poor are helps define how to move from generalised consumer subsidies to a targeted consumer subsidy. Most monetary policy reform has focused on liberalising interest rates and capital markets. Since experience with these reforms in Africa has been relatively limited, the impact on food security is unclear. Rather more dramatic has been the result of public sector reform. These reforms, all of which have centred on reducing state intervention in the economy, have normally included retrechment of civil servants and dissolution of publicly held companies. For those retrenched, or let go, this has meant an immediate loss of income and reduced access to food.

Household food security concerns the microeconomics of the household. In particular, it describes the use of food in the house, access to it by various members of the household and the role of gender. In work done at the World Bank on household food security, gender has assumed a central importance. Women's varying capacities for income generation, their generally reduced access to education (and sometimes health 
facilities), and their apparent willingness to put a high priority on family food security, means that an understanding of household economics is crucial. In addition, household decisions concerning numbers of children are one of the most critical variables in the overall longer, run food balance. As with macroeconomic change, microeconomic change affects both food supply and food consumption. For instance, increased education of women can lead to better knowledge of nutrition and improved food security, even at a stable level of access. However, improved female education will also lead to improved incomes for women, a high proportion of which would be used for food. Similarly, better extension services for women (indeed, any such services at all) can lead to increased production and greater food availability.

Food availability at the national level depends on domestic agriculture production and imports, and at the household level on household production and other income. In most countries of Africa, agriculture production is rainfed and therefore, highly susceptible to drought. In addition, technical packages adapted to Africa's agronomic and cultural conditions which have dramatic effects on yield are largely unavailable. As a result, there is a considerable emphasis on agriculture production in food security strategies for Africa. In part, this requires improved farmer support services (extension, credit and physical inputs). It also requires better and more appropriate research. But for Africa food imports are (and will remain) a necessary complement to domestic production. Even after food output in Africa begins to rise at a rate above population growth rates (as it should), many countries and virtually all households will not be self-sufficient in food. It would not be economically sensible to be so. Food security can be assured by assuring regular access to purchased food, in some cases more easily than growing the food oneself. This obviously requires income; foreign exchange at the national level and off-farm employment at the household level.

It is national or household income which on the whole drives food consumption. At base, the 'entitlements' approach to food security is income driven; if one is poor, or the price of food 'too' high, food availability does not matter. It is in this regard that food insecurity is effective in identifying who the poor are. Ensuring access to food depends on specific local conditions. In some cases, such as drought and disaster, food security is assured by free provision of relief food. More commonly, however, access is assured in the first instance by providing income to the poor, and/or transfers in the form of public services for health and education.

What knits together the previous discussion is the function of markets and the state of the physical infrastructure. Markets are the medium which transmits macroeconomic change to the household, and which determine, in part whether agricultural output is available for consumption when needed, and at an affordable price. From a food security. standpoint, the most obviously important market to consider is the goods market, which intermediates between food producer and consumer. (Labour, capital and land markets also have an impact on food security, but are likely to be less important.) Goods markets are strongly influenced by government policy, particularly insofar as governments intervene to provide storage and handling facilities. In addition, the state of public infrastructure (roads, waterways, communication, etc.) determines the degree to which markets are integrated and efficient. There are countries (Madagascar is an example) which at an aggregate national level produce more than enough food to feed their populations, but where there are regional shortages owing to fractured markets and deteriorated infrastructure.

The process by which World Bank staff have approached food security analysis has varied from one country to another. Some general themes appear, however. First, food security analysis at the World Bank has had a strong macroeconomic policy link. Given the emphasis on policy led structural reform, this is both appropriate and unsurprising. Second, food security analysis has on the whole had a strong rural orientation, for the obvious reason that this is where part of the food availability problem is to be resolved, but also, for the less obvious reason that this is where much of the insufficient access to food is located as well. A third process point is that food security analysis has driven Bank staff to investigate new sources of information for a better understanding of food poverty. Primary among these information sources is the extensive but largely unintegrated data on nutrition status. Many governments, as well as other bilateral and multilateral donors, have been active over the years in researching issues of nutrition and individual welfare. Food security analysis has, therefore, led to a higher degree of donor collaboration. As a result, of the food security field work carried out by Bank staff, over one half has comprised joint missions with other donors.

Some important common themes have emerged from the World Bank Centre's food security analysis. For instance, all the studies have concluded that accelerating agriculture's growth is a necessary condition for food security in Africa. While food selfsufficiency should not be the goal, Africa's food selfreliance must be based on higher levels of domestic production. Another common finding has been that looked at from the standpoint of nutrition indicators, especially among children, the level of food poverty in Africa is greater than anticipated. All of the studies have struggled with the issue of how to implement targeted interventions effectively and efficiently in Africa. While there has been no dispute that targeted 
interventions are the only realistic approach for Africa, the way to design them is far from clear. One example, which has been proposed for Mozambique is to subsidise inferior grains. Finally, the analysis of food security issues at the World Bank has reinforced the importance attributed to gender in programming sound development strategies.

\section{Conclusion}

Food security is a useful principle to organise a country's public policy. It acknowledges the importance of economic growth, but is equally concerned with the distribution of the benefits of growth. In using the concept, there is an analytical need to identify clearly policy and investment recommendations of relevance to food security as distinguished from those which are not. By the balance it brings to growth strategies and its impact on the poor, food security leads to public policies which are different in tone from 'growth only' approaches. For the analyst approaching food security, choices and priorities are important. Making these choices will differentiate a food security led development strategy from any other. This paper provides a basis on how to go about making these choices.

\section{References}

Arndt, H. W., 1987, Economic Development: The History of an Idea, University of Chicago Press

Gunatilleke, Godfrey, 1989, Government Policies and Nutrition in Sri Lanka, Cornell University, Ithaca, New York

Riley, Barry, February 1990, Relationships between Food Security and Nutrition Concerns in Africa, unpublished World Bank document

World Bank, 1986, Poverty and Hunger: Issues and Options for Food Security in Developing Countries, Washington, DC

-1988, The Challenge of Hunger in Africa, Washington, DC

-1989, Sub-Saharan Africa: From Crisis to Sustainable Growth (Referred to as LTPS), Washington, DC

-1989, Mozambique Food Security Study, Washington, DC -1990, World Development Report 1990, Washington, DC 